\title{
Nanofiber nets in prevention of cicatrisation in spinal procedures. Experimental study
}

\author{
Jarosław Andrychowski ${ }^{1,2}$, Małgorzata Frontczak-Baniewicz ${ }^{3}$, Dorota Sulejczak ${ }^{4}$, Tomasz Kowalczyk ${ }^{5}$, \\ Tomasz Chmielewski ${ }^{5}$, Zbigniew Czernicki, ${ }^{1,2}$, Tomasz Aleksander Kowalewski ${ }^{5}$ \\ 1Department of Neurosurgery, Mossakowski Medical Research Centre, Polish Academy of Sciences, Warsaw, 2Department of Neurosurgery, \\ Medical University of Warsaw, ${ }^{3}$ Electron Microscopy Platform, Mossakowski Medical Research Centre, Polish Academy of Sciences, \\ Warsaw, ${ }^{4}$ Department of Experimental Pharmacology, Mossakowski Medical Research Centre, Polish Academy of Sciences, Warsaw, \\ Institute of Fundamental Technological Research, Polish Academy of Sciences, Warsaw
}

\begin{abstract}
Excessive cicatrisation or epidural fibrosis in the operative field is an inappropriate event occasionally occurring after neurosurgical procedures (i.e., spine procedures and craniotomies). This excessive process may disturb the postoperative course and render reoperations more difficult and risky. The literature describes this phenomenon as accompanying up to $20 \%$ of neurosurgical procedures. The scar tissue that forms postoperatively adheres to the dura mater, penetrates into the spinal canal and can cause narrowing symptoms, neurological deficits and pain. The incidence and spread of this excessive scar or epidural fibrosis can be prevented through the modification of the surgical technique by incorporating endoscopic or microscopic access to minimize the operative field and the use of isolating substances (autogenous or heterogeneous) administered intraoperatively.

The aim of this experimental study was to morphologically assess the cicatrisation process, adhesion and to prevent excessive scar formation with the local use of membranes manufactured by an electrospinning process (nanotechnology). We also investigated whether the biodegradable nanofibrous net triggers or modifies the immunological response or the local inflammatory process.

Micro-nanofibrous membranes were produced by the electrospinning process. A biodegradable, medically certified copolymer poly(L-lactide-co-caprolactone) (PLCL) was used as the electrospun material.

An experimental rat model was used in this study. Experimental and control groups were formed with specified follow-up times of 4, 14 and 30 days. During the operation, a two-level laminectomy in the thoracic segment was performed. The operative field was divided into two regions. Isolating material was used on the dura mater and surface of the spinal cord in the area where the laminectomy was performed. The material was analysed with the use of light and electron microscopy.

Local cicatrisation can be modified using nanomaterials. Scar formation and epidural fibrosis can be limited and modified locally. No local inflammation process was observed.

Initial observations indicate the potential for the effective use of materials obtained in the electrospinning process to prevent cicatrisation.
\end{abstract}

Key words: neurosurgery, cicatrisation, epidural fibrosis, copolymer, poly(L-lactide-co-caprolactone), nanofibrous net, rat model. 


\section{Introduction}

The first papers on cicatrisation or the process of epidural fibrosis after neurosurgical procedures date back to the 1970s $[4,26,27,43]$. Developments and progress in the field of spinal surgery have caused the number of patients undergoing these procedures to multiply [4]. Long-term postoperative observations have demonstrated excessive cicatrisation within the spinal canal and its dural and neural components to be one of the factors adversely affecting the postoperative period $[10,26,28,30,41,42]$. We observed this improper cicatrisation involving the neural elements after the dura and arachnoid matter damage in the different neurosurgical procedures. Epidural fibrosis is considered to be one of the mechanisms that may be responsible for postoperative pain [30,41,42]. Cicatrisation is a part of the natural and normal healing process that makes any surgery possible, but excessive or inappropriate scar formation is an adverse process in the surgical context.

In neurosurgery, excessive cicatrisation can lead to neurological symptoms and pain. Its prevention is based on three methods specifically designed to significantly reduce epidural fibrosis, adhesion and/or excessive cicatrisation. The first method is based on minimizing the surgical field exposure using microscopic and endoscopic approaches $[16,27,28,43]$. The second method involves the formation of an isolation barrier made of autogenous materials, and the third method uses heterogeneous materials (gels, separate films, artificial membranes) intended to prevent excessive scarring or modify the process of scar formation. This problem and its related adverse effects (e.g. pain) continue to affect many different branches of human medicine despite many studies that have demonstrated promising results using these materials. Over the last 10 years, different artificial materials have been used following discectomies, and their effectiveness has been assessed. These materials include Gore-Tex surgical membranes [29], gels with polyethylene oxide and carboxymethylcellulose [12,35], and sodium hyaluronate [19]. Artificial materials used in neurosurgical procedures can cause a disadvantageous granulomatous process [1]. Experimental studies in recent years have also used hyaluronic acid, hemostatic gelatin (Floseal; Baxter International Inc.), DuraGen, monoclonal antibodies, mitomycin and aprotinin, TachoComb, bioresorbable films and hydrogels $[3,5,7,8,19,22,25$, 34,40].
On the other hand, following the Central Nervous System damages the glial scar formation is a reactive cellular process involving astrogliosis [13] and it is the mechanism to protect and begin the healing process in the nervous system. It is known that the absence of the glial scar has been associated with impairments in the repair of the BBB (blood brain barrier) [9].

The present paper reviews available methods to prevent improper scar formation and provides an assessment of the local use of new biodegradable membranes manufactured using nanotechnology (electrospinning of nanofibers) to prevent excessive scarring.

\section{Material and methods \\ Nanofibrous materials}

Membranes manufactured using electrospinning were used to create an anti-scarring barrier in an experimental (rat) laminectomy model.

Electrospinning (electrical spinning) is a convenient method for producing nanomaterials. Nanofibers are manufactured at room temperature, which enables the production of membranes made of temperature-sensitive materials (e.g. polyhydroxy esters) [24] or proteins [23]. Different types of drugs or even living cells can be incorporated into the material. Materials of biological significance are produced using the electrospinning process $[2,14,31]$, and described in detail elsewhere [33]. Briefly, when the stream of a polymer so lution is subjected to a high electrical field (range: $0.1-1 \mathrm{kV} / \mathrm{cm}$ ), the filament of the solution begins to bend and spin, creating a thin yarn of polymer (diameter ranging from $2 \mathrm{~nm}$ to micrometer size).

In our experiment, the spinning distance was $20 \mathrm{~cm}$, the electric potential was $15 \mathrm{kV}$, and the solution throughput was $0.500 \mu \mathrm{l} / \mathrm{h}$. A rotating drum covered with aluminium foil served as a nanofibrous mat collector. The polymer used for electrospinning was poly(L-lactide-co-caprolactone) (PLCL), which was composed of 70\% L-lactide and 30\% caprolactone units and is known commercially as Purasorb 7015 (Purac Biochem BV, Gorinchem, the Netherlands). The electrospinning solution was made of $9 \%$ polymer dissolved in a mixture of solvents (chloroform + dimethylformamide, mass proportions $16: 1)$.

Poly(L-lactide-co-caprolactone) is medically approved material and is a member of a family of polyesters used for surgical sutures, drug delivery systems and antiadhesion materials. This research is based on shaping a known material into a new form. 
Membranes produced by the electrospinning process have limited permeability, especially for cells, but constant drainage of their degradation products is maintained. In addition, oxygen, nutrients and metabolites can easily diffuse through the membrane. The membrane had a thickness of approximately $60-100 \mu \mathrm{m}$, was formed of fibers that were 0.5-1.8 $\mu \mathrm{m}$ thick (Fig. 1) and was more than $80 \%$ porous. As such, this material was thick and stable enough to separate healing tissues. Furthermore, it was gradually degraded to minimize the formation of a connective tissue scar, and it was especially effective at minimizing interactions between tissues. It is also important not to leave any foreign material behind to prevent long-term tissue irritation and subsequent scarring.

Degradation of the membrane produces either natural metabolites (lactic acid) or their non-toxic analogues (6-hydroxyhexanoic acid). Both acids are irritating to tissues at high concentrations due to their chemical character, and 6-hydroxyhexanoic acid is 10 times weaker than lactic acid. The fibrous membrane maintained its strength comparable to the performance of solvent-casted membranes, but it was formed from far less material. Thus, inflammation was significantly reduced due to the reduced contact with irritating hydroxyl acids that form during hydrolysis. The material used was also specifically designed not to degrade rapidly so that the healing tissues could be isolated, but it did degrade in a reasonable amount of time to prevent scar formation. The comparison of the degradation time of polyesters in vivo is as follows: (few weeks) PLGA >>PLA>PLCL70 >>PCL (up to 2 years). PLGA corresponds to poly(lactic-co-glycolic acid), PLA is poly(lactic acid), PLCL is Purasorb 7015 containing 70\% lactate units and 30\% 6-hydroxyhexanoate units, and $\mathrm{PCL}$ refers to poly(6-hydroxyhexanoic acid), also known as polycaprolactone.

\section{Operative procedure}

An animal model (Wistar rats) was used. The protocol for all experiments was approved by the local Animals Care Committees in accordance with the policies established by the Polish Council on Animal Care No. 15/2010 (IV Local Ethical Committee, 00-725 Warsaw $30 / 34$, Chelmska Str.). Animals (eight rats in every experimental group) - adult male Wistar rats weighing 150 to $250 \mathrm{~g}$, were anesthetized with $2 \%$ halothane and 2:1 mixture of nitrous oxide and oxygen. The animals were placed on a heating pad at $36^{\circ} \mathrm{C}$ during surgery,

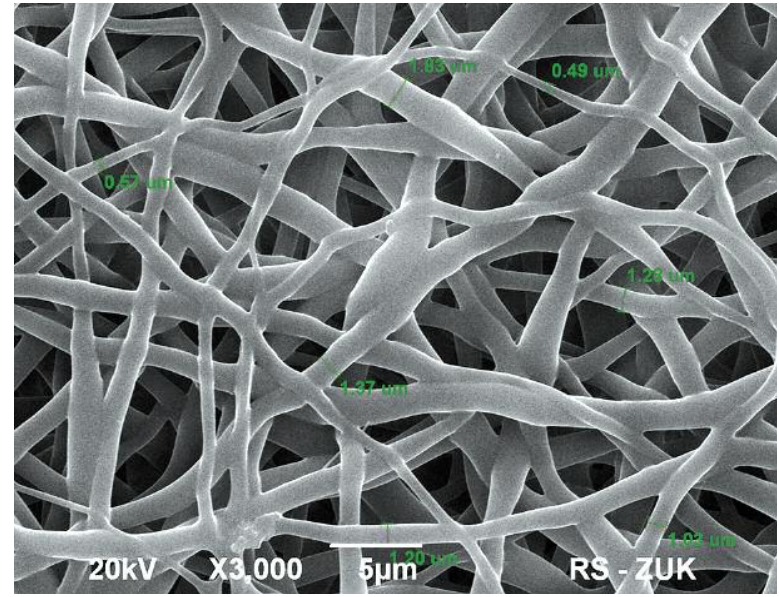

Fig. 1. The structure of an appropriate nanomaterial without defect; thickness approx. $60 \mu \mathrm{m}$, thickness of fibers $0.5-1.8 \mu \mathrm{m}$.

and then a laminectomy at two levels was performed at the thoracic region to expose the spinal cord and dura.

The thoracic spinal canal was opened using a microsurgical technique. The operation procedure was performed by an experienced neurosurgeon with the use of a high speed drill, operative microscope and a set of microsurgical instruments. The size of the microsurgical instruments was the same for human microsurgery. The two-level laminectomy procedure was performed and the surgical field was divided into two parts. After removing the bone, the operative field dimensions were approx. $4 \mathrm{~mm}$ width and 8-9 $\mathrm{mm}$ length. In one part of the operation field, the dura covered the spinal cord and was intact, in the second one, the dura was opened and removed using a microsurgical technique with micro knife and micro scissors. The part of the removed dura was approx. 3-4 mm width and $4 \mathrm{~mm}$ length. In the operation field, properly prepared two pledges of the nanofiber net were placed, one of them covered the dura and the second one covered the spinal cord. The lateral edge of nanofiber pledge was placed microsurgically under the bone of the spinal canal in order to do fixation.

The animals were divided into specified groups. The A group was a sham in which the full procedure (two-level laminectomy - TLL) was conducted. The B group was subjected to TLL with application of a nanofiber net to the surface of the undamaged dura and undamaged spinal cord. The $C$ group had damaged spinal cord surface. The D group was subjected to TTL 
Table I. Description of the experimental groups

\begin{tabular}{|c|c|c|c|}
\hline $\begin{array}{l}\text { Experimental group } \mathrm{A} \\
\text { (8 rats) }\end{array}$ & $\begin{array}{l}\text { Experimental group } \mathrm{B} \\
\text { ( } 8 \text { rats at the ever time points) }\end{array}$ & $\begin{array}{l}\text { Experimental group } C \\
\text { ( } 8 \text { rats at the ever time points) }\end{array}$ & $\begin{array}{l}\text { Experimental group D } \\
\text { ( } 8 \text { rats at the ever time points) }\end{array}$ \\
\hline $\begin{array}{l}\text { Sham-operated animals } \\
\text { subjected to: } \\
\text { a full procedure (two-level } \\
\text { laminectomy - TLL) }\end{array}$ & $\begin{array}{l}\text { Animals subjected to: } \\
\text { TLL and the application } \\
\text { of a nanofiber net to the sur- } \\
\text { face of the undamaged dura } \\
\text { and undamaged spinal cord }\end{array}$ & $\begin{array}{l}\text { Animals subjected to: } \\
\text { TLL and damage of the spinal } \\
\text { cord surface }\end{array}$ & $\begin{array}{l}\text { Animals subjected to: } \\
\text { TLL and application of a nano- } \\
\text { fiber net to the surface } \\
\text { of the damaged spinal cord }\end{array}$ \\
\hline
\end{tabular}

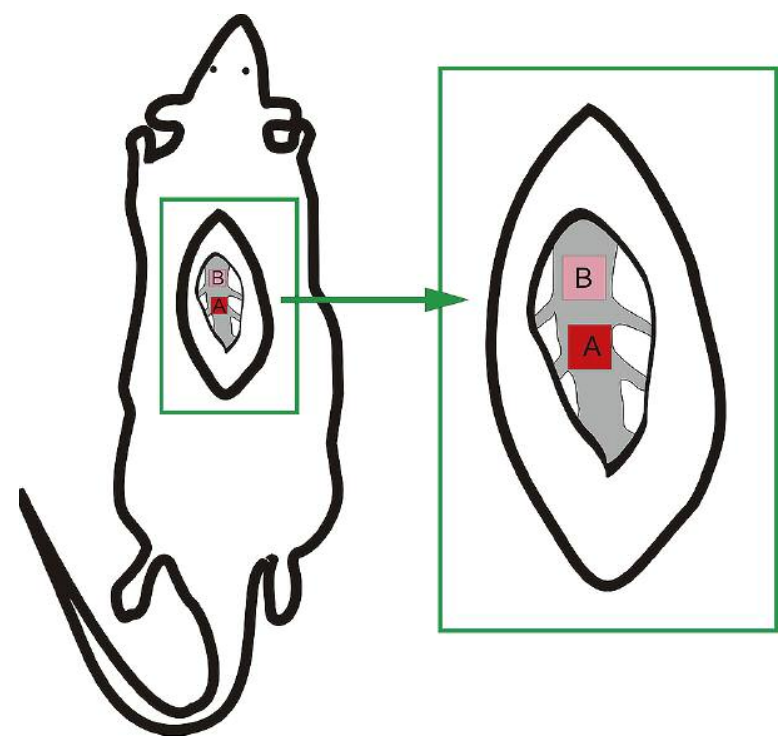

Fig. 2. Depiction of the operative field and the application of nanofiber nets. A - nanofiber net applied after removal of the dura mater and B a nanofiber net applied on the dura mater surface.

with application of a nanofiber net to the surface of the damaged spinal cord (see Table I).

The nanofiber nets were always applied to two locations simultaneously (A and B): A - nanofiber net was applied after removing the dura mater, and $B$ nanofiber net was applied on the dura mater surface (Fig. 2).

Then, a multi-layer suturing technique was used for closure and no spinal liquorrhea was observed. In postoperative care animals remained under standard laboratory conditions with free access to food and water, and analgesic drugs (paracetamol) were administered.

The collected specimens were analyzed on days 4, 14 , and 30 following perfusion with the use of light and electron microscopy.
After the specified experiment time intervals, the animals were anesthetized and perfused, and their spinal cord specimens were harvested for subsequent light microscopy immunostaining and electron microscopy. Rats were anaesthetized with Nembutal (80 mg/kg b.w.) and perfused through the ascending aorta with $2 \%$ paraformaldehyde, $2.5 \%$ glutaraldehyde in $0.1 \mathrm{M}$ cacodylate buffer, $\mathrm{pH} 7.4$ (for ultrastructural morphological studies) or with 4\% paraformaldehyde in $0.1 \mathrm{M}$ phosphate buffer (PBS), pH 7.4 (for light microscopy studies) for $20 \mathrm{~min}$ at $20^{\circ} \mathrm{C}$. The tissue was sampled from the spinal cord according to the experimental procedure (see Table I). The tissue from control animals was sampled from the matching region of the intact spinal cord.

The material for electron microscopic studies was further fixed in the same solution (2\% paraformaldehyde, $2.5 \%$ glutaraldehyde in $0.1 \mathrm{M}$ cacodylate buffer, $\mathrm{pH} 7.4$ ) for $20 \mathrm{~h}$ and postfixed in a mixture of $1 \%$ osmium tetroxide $\left(\mathrm{OsO}_{4}\right)$ and $0.8 \%$ potassium ferricyanide $\mathrm{K}_{4}\left[\mathrm{Fe}(\mathrm{CN})_{6}\right]$. Then, the material was processed for transmission electron microscopy (JEM-1200EX, JEOL, Japan).

The material for light microscopic studies designed for immunohistochemical (IHC) investigations was further fixed in the same solution (4\% paraformaldehyde in $0.1 \mathrm{M}$ phosphate buffer [PBS], pH 7.4) for $2 \mathrm{~h}$. Specimens were subsequently infiltrated in $10 \%$ sucrose in PBS, followed by $20 \%$ and $30 \%$ sucrose solutions infiltration for the following days and then cut on 40- $\mu \mathrm{m}$ thick sections on a cryostat (Leica, Germany). IHC reactions staining were carried out on free-floating spinal cord sections. Primary antibodies (Abs) against GFAP ( $1: 1000$, Chemicon, USA) and Vimentin (1: 400, Santa-Cruz, USA) and secondary antibodies conjugated to HRP (1 : 1000, Bio-Rad, USA) were used. The HRP reaction product was visualized with an SG kit (Vector, Vector Labs, USA). For the analysis of cell morphology several dyes were used. They were haematoxylin \& 

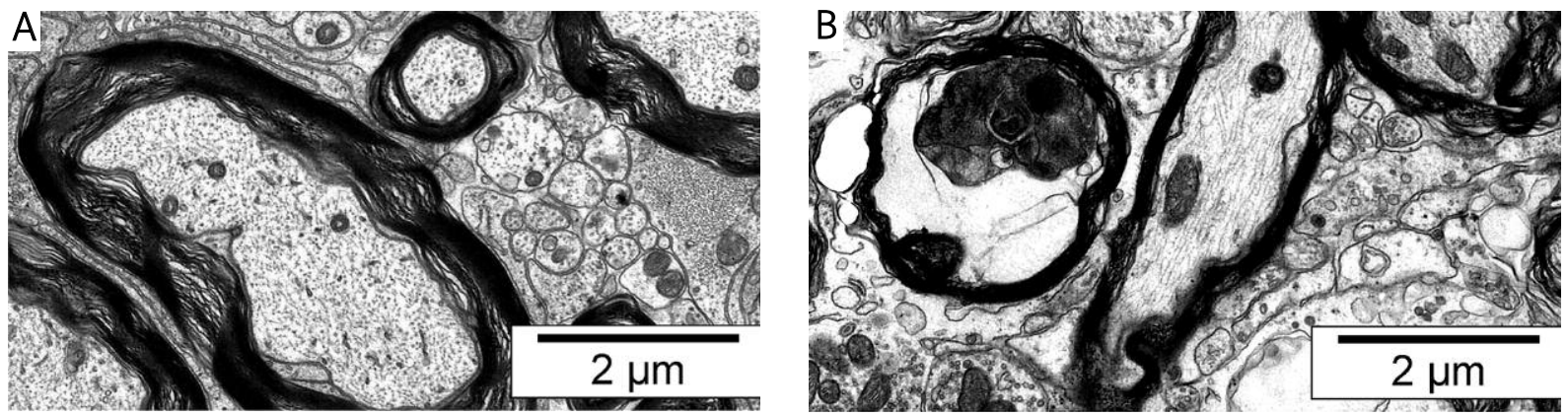

Fig. 3. Ultrastructural features of neurodegeneration. Left microphotograph shows unchanged neuronal axons. On the right microphotograph, signs of axonal degeneration are observed.

eosin (Sigma-Aldrich) and bisbenzimide (Hoechst; Sigma-Aldrich).

To control the immunostaining specificity we performed an experiment in which the primary antibodies were omitted in the incubation mixture. In this experiment we did not detect immunolabeling within the analysed spinal cord sections.

\section{Results}

The examination of the spinal cord tissue from the sham group showed no astrocyte induction and no (glial) scar formation. No neurodegeneration occurred in any of the experimental time intervals (Fig. 3, left panel).

In the group of rats in which the nanofiber net was applied to the surface of the undamaged spinal cord, no morphological features of neurodegeneration were noted (data not shown). The presence of single macrophages was observed only at the early time points (4 days after application of the nanomaterial). Some astrocytes that were positive for glial fibrillary acidic protein (GFAP) and a few vimentin-immunoreactive astroglial cells were detected (Fig. 4, left panel). The reaction was temporary and disappeared at the late time point (30 days, data not shown) while it persisted within the spinal cords derived from group C. The results were confirmed by electron microscopic analysis of the experimental material. In cases where the spinal cord tissue was in contact with the nanofiber pledged, no fibroblast cells were identified (data not shown).

The spinal cord tissue sections taken from animals with spinal cord damage (group C) demonstrated massive neurodegeneration characterized by the shrinkage of cells and their processes (Fig. 3, right panel; Fig. 5) and neuronal death at the site of damage.
At 4 days, cellular death was observed in the vicinity of the areas of damage (group C). At 14 days, the region of the spinal cord affected by degeneration and tissue loss grew. Finally, at 30 days after injury, major portions of the dorsal horns of the spinal cord were affected (data not shown). Glial scars composed of astrocytes formed on the wound surface. Astrocytes were positive for GFAP and some astroglial cells forming the scar were positive for vimentin (Fig. 4, middle panel). Massive astrogliosis and macrophage infiltration were observed in the vicinity of the damage, indicating inflammation (see Table II). Our earlier observations show that macrophage infiltration is detected up to 10-12 days following the operation.

The ultrastructural imaging confirmed the presence of glial scars formed by numerous astrocytes rich in GFAP fibers (Figs. 5A-B). The presence of macrophages was also confirmed (Fig. 5B). Some capillary blood vessels with the ultrastructural features of young vessels were also identified (Fig. 5A). In the vicinity of the glial scar, many fibroblasts in tight contact with collagen fibrils were also observed (Figs. 5A-B). The epidural fibrosis invasion was observed. Migrating fibroblasts invaded dura mater and formed connective tissue barrier (data not shown).

The material derived from the animals subjected to laminectomy in which a nanofiber net was applied to the surface of the damaged spinal cord (group D) demonstrated signs of degeneration only at the early post-lesion time points. The moderate and temporal astrogliosis was observed (Fig. 4, right panel). In the injured area, a thin layer of astrocytes rich in GFAP fibrils was present (Fig. 6). No excessive fibroblast proliferation was observed (Fig. 6). The data indicate that the nanofiber net reduced epidural fibrosis in our model. Only single macrophages were found at the early time points following the injury (see Table III). 


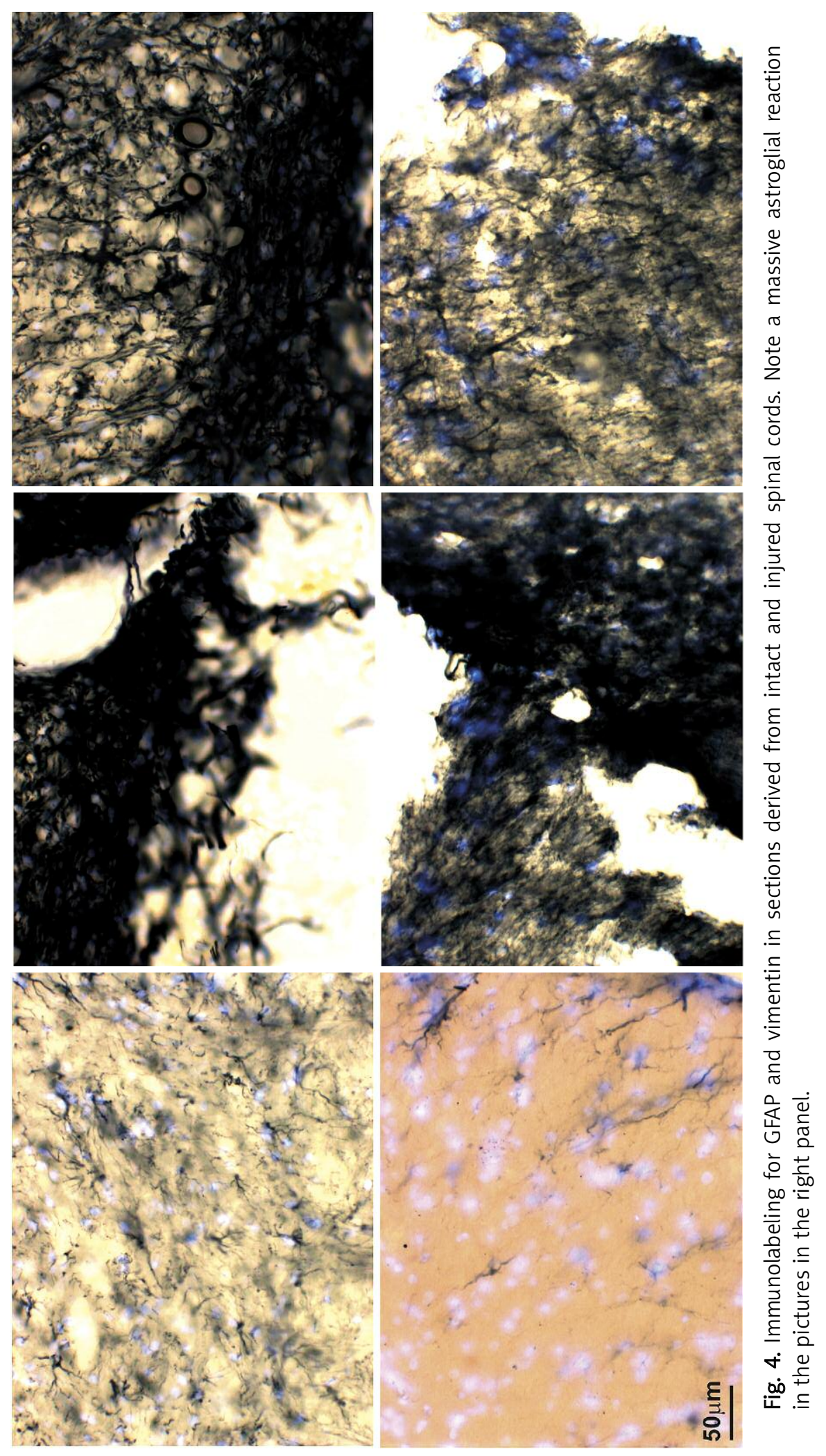



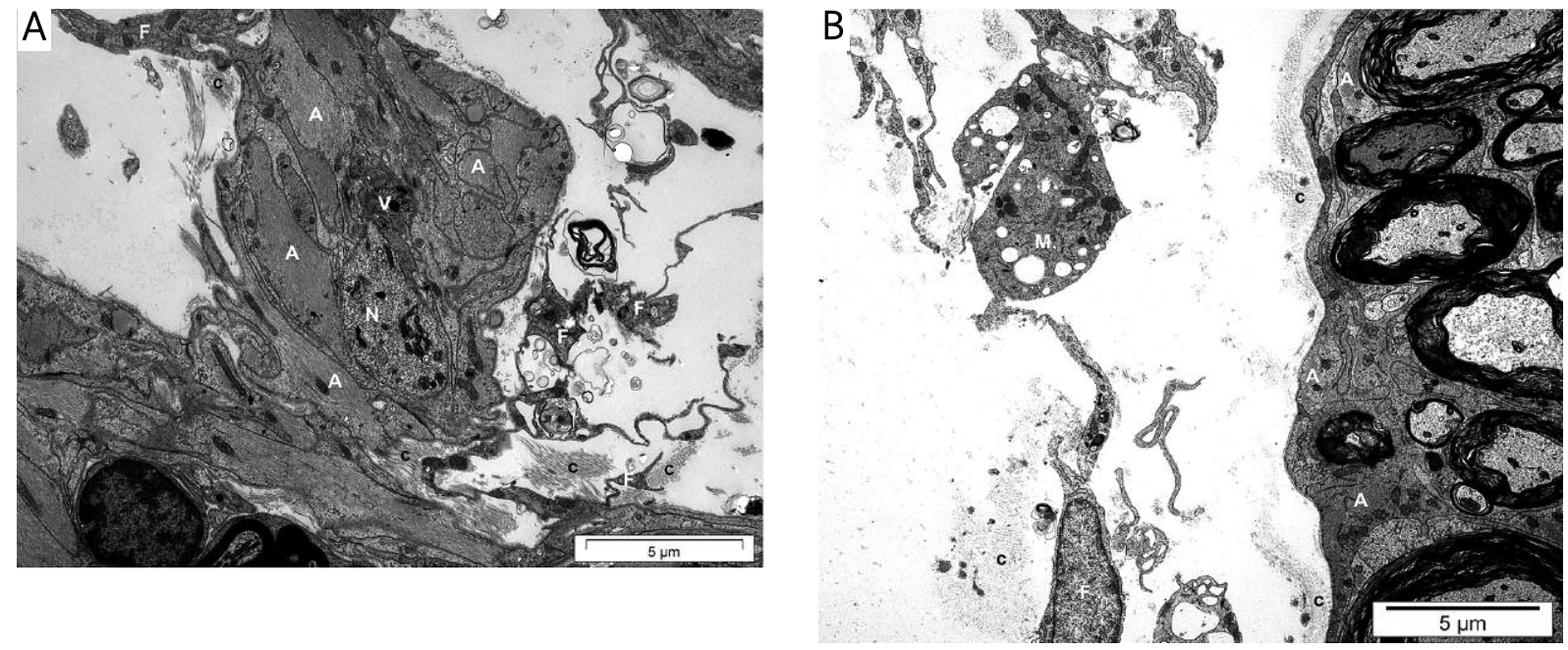

Fig. 5. Ultrastructural features of neurodegeneration and glial scars of an injured spinal cord. Microphotographs show a damaged area (A) and a perilesional region (B) of the spinal cord. A - astrocytes rich in GFAP, $V$ - new vessel, $F$ - fibroblasts, $N$ - degenerating neuron, $\mathrm{C}$ - collagen, $\mathrm{M}$ - macrophage.

\section{Discussion}

The ideal isolation material for local use in the neurosurgical field must comply with numerous requirements. It should prevent local excessive cicatrisation, avoid the adhesion of tissues but at the same time, it should not inhibit the healing process. In neurosurgical procedures, this material should isolate neuronal structures from the adjacent tissues to prevent scar tissue formation and separate different tissues from each other. Isolation materials are particularly essential for cases of reoperation because they reduce the additional risk of liquorrhea and damage to the neuronal tissue. These materials also must not induce local toxicity or any other local mechanical or chemical effects on adjacent structures (i.e., dural sac and nerve root) that might lead to structural changes. Other important characteristics include not provoking a local inflammatory response but it is known that artificial materials can induce granulomatous and foreign body response [1]. The material itself as well as its degradation products must be recognized by the body as natural metabolites. Both the inherent characteristics and manufacturing process of the isolation material must allow for the determination of the biodegradation period following in situ insertion into the tissues.

Excessive cicatrisation observed after spinal canal procedures is a clinical problem and is assumed to contribute to poor neurosurgical outcomes in approximately
Table II. The number of macrophages found within 20 microscopic fields of observation (6 animals per group)

\begin{tabular}{|lllllllll|lllll|}
\hline & & \multicolumn{3}{c|}{$\begin{array}{c}\text { Group C 4 days } \\
\text { following the injury }\end{array}$} \\
\cline { 2 - 3 } & \multicolumn{3}{|c|}{ Rats } & & \multicolumn{3}{c|}{ Rats } \\
\hline $\begin{array}{l}\text { Number of } \\
\text { macrophages }\end{array}$ & 0 & 0 & 1 & 0 & 0 & 1 & 47 & 54 & 42 & 50 & 46 & 43 \\
\hline
\end{tabular}

$15-20 \%$ of patients $[15,26,30,41,42]$. The assessment of poor neurosurgical outcomes attributed to excessive cicatrisation and contributing to "failed back syndrome" should involve exclusion of other causes, such as inadequate surgical methods (with its overarching assumption that disc herniation can be treated effectively without the use of optical techniques), recurrent disc herniation, foraminal stenosis, postoperative spinal instability and neuropathic pain as a result of nerve root damage. Symptoms can be attributed to excessive cicatrisation after a proper differential diagnosis has been made. Clinical evaluation is particularly difficult, and it is based on the clinical symptoms reported by the patient (i.e., nerve root pain and low back pain) that need to be correlated with magnetic resonance imaging (MRI) results. MRI provides precise visualization of scar tissue. In approximately $24 \%$ of patients after spinal canal surgery, the radiological evaluation shows a scar surrounding and infiltrating 

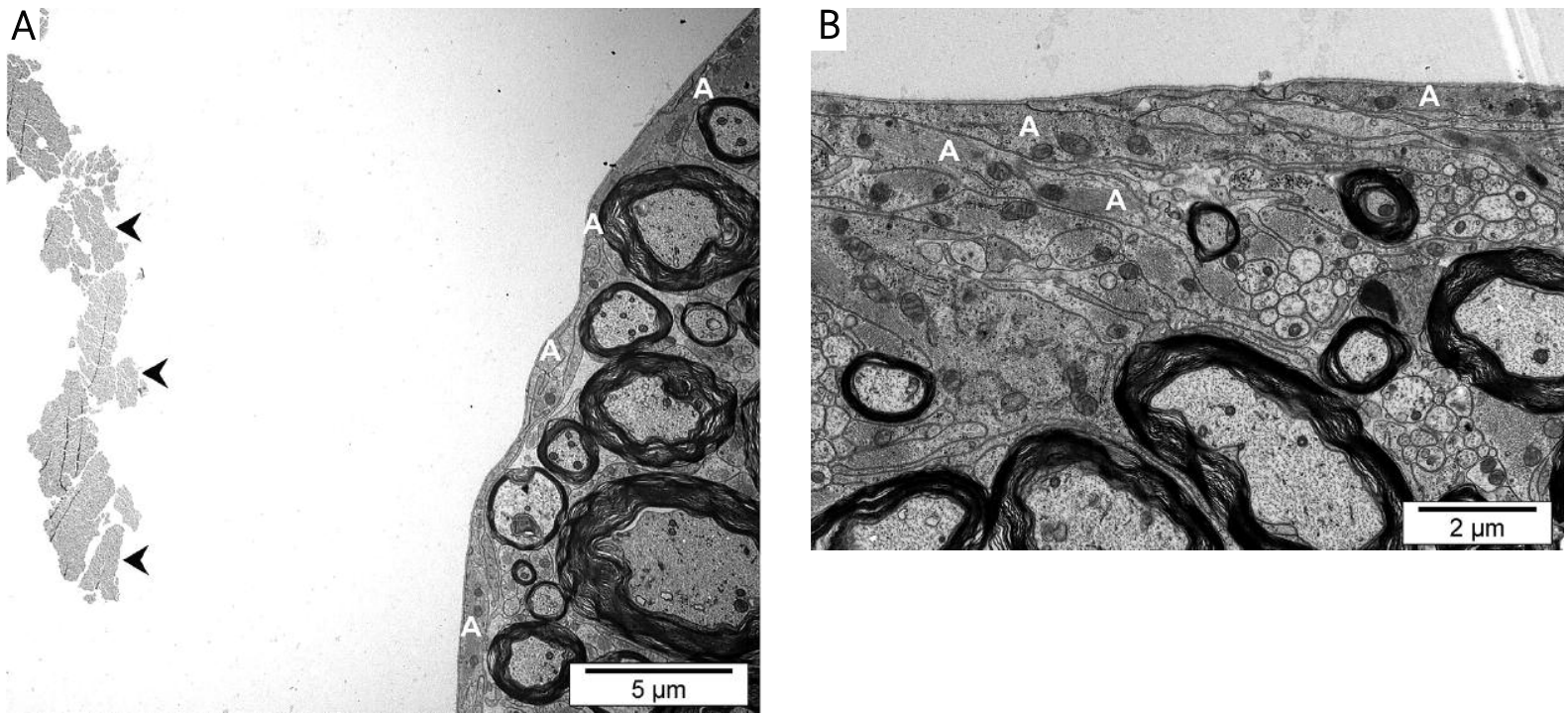

Fig. 6. Microphotographs of damaged spinal cords with the applied nanofiber net four (A) and 14 days (B) following the operation. Note the unchanged spinal surface and the absence of fibroblasts and macrophages. Arrowheads point to the remnants of the nanofiber net. A - astrocytes rich in GFAP.

Table III. The number of macrophages found within 20 microscopic fields of observation ( 6 animals per group)

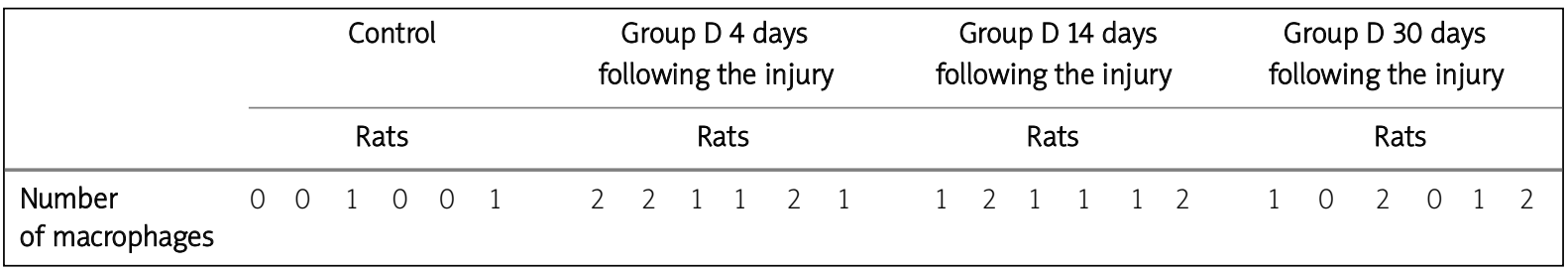

the dural sac and nerve roots, thereby affecting their function.

The materials used in the prevention of cicatrisation in human surgery include polytetrafluoroethylene, autogenous adipose tissue, protein polymers, hyaluronate, Adcon-L, Oxiplex/Sp, DuraGen, and DuraSeal Xact Adhesion Barrier (DSX) [10,11,12,16,18,20,21]. These products are currently available and used throughout the world. Many neurosurgical centres in Poland utilise tachocomb (Nycomed) and have demonstrated its effectiveness in preventing cicatrisation. The variability of the products that are currently available and utilized indicates that the problem of excessive cicatrisation is still a concern, and no comprehensive countermeasure has been identified. No studies have demonstrated a complete elimination of excessive cicatrisation. Some publications have reported promising results; however, the ultimate solution to the problem has not been identified.
One of the most promising adhesion barrier preparations is Adcon-L (USA), which is indicated for local administration in the surgical field and acts as a fibroblast inhibitor, decreasing collagen production. Such activity has been confirmed by MRI. Unfortunately, systemic adverse effects of this formulation have been reported, in addition to fistula formation. As a result, the inhibition of local fibroblasts during postoperative wound healing is no longer considered a feasible preventive method, and clinical observations did not demonstrate any positive effect of this approach in the postoperative period [15-18]. Other methods used to create the anti-adhesion barrier include the application of isolation gel (carboxymethylcellulose and poly(ethylene oxide) (PEO)-based Oxiplex gel, US). However, clinical observation has not demonstrated any positive effects of these formulations in the postoperative period. Furthermore, Oxiplex is contraindicated whenever intraoperative liquorrhea is suspected $[20,21,35]$. 
The use of synthetic hydrogel (DSX) to form an antiadhesion barrier is a relatively new approach. This barrier disappears approximately 2 months after the surgery, thus constituting an effective anti-adhesion prophylaxis. DSX is also used in other surgical contexts including craniotomies and other surgical specialties. Unfortunately, no long-term clinical observation data have been published to date $[6,32]$.

Many experimental studies have been conducted with the aim of developing new formulations to prevent excessive cicatrisation $[5,8]$. Studies have also been performed with membrane films as anti-adhesion barriers. However, the properties of these films may induce a local inflammatory response.

During the in vivo hydrolytic degradation of polyhydroxy acids (PHA), monomeric hydroxyl acids are formed. Solvent-casted polymeric membranes accumulate these hydroxyl acids. The acids serve as autocatalysts that speed up the hydrolytic degradation process, and the thicker the materials, the faster the degradation. At the final stage of hydrolysis, there is not enough room for the acid in the polymer, causing a burst of hydroxyl acids that may then cause inflammation.

The fibrous structure is also important for membrane stability. Thick materials made of polyhydroxyesters undergo hydrolytic degradation when implanted, and the degradation products accumulate in the membrane. The method used to prevent the accumulation of hydroxyl acids is the creation of membranes from nanofibers that are easily drained by biological fluids. A class of biopolymers, aliphatic polycarbonates, has been extensively researched by previous authors [36-39] and was found to be free of autocatalytic hydrolysis.

The new experimental isolating material assessed comprises electrospun membranes formed from micro- and nanometre-sized fibers. The degradation products of these membranes are drained by biological fluids, and thus no autocatalysis, accumulation or subsequent burst of hydroxyl acids occurs, minimizing inflammation. Another advantage of electrospun nanofibers is their similarity to extracellular collagen matrix, which is native to cells.

The presented material manufactured by electrospinning (nanotechnology) meets the isolation expectations in an experimental model. This initial research indicates that this material modifies the cicatrisation process, demonstrates anti-adhesion potential and forms a fibroblast matrix. Other properties, such as the technological potential to modify the biodegradation time, lack of an inflammatory response in adjacent tissues and neuronal elements, and its components and metabolites (lactates), suggest that this material could be considered for application in postsurgical cicatrisation prevention.

\section{Conclusions}

The results gathered demonstrate that the isolating material composed of nanofibers does not induce inflammation in the animal (rat) model. This material does not induce either a connective tissue or glial scar formation or neurodegeneration when placed on healthy tissue. The nanofiber net applied on the injured spinal cord can reduce formation of both investigated types of scar. These results suggest that the application of nanofiber nets positively contributes to the healing process of neurosurgical wounds.

\section{Acknowledgements}

This research was supported by ministerial resources under the grant Research Project no. NN 403 176 939/2010.

The results were subjected to Polish patent application no. 395894 2011-08-08 "Zastosowanie siatek izolacyjnych wytwarzanych z nanowłókien polimerowych do zapobiegania bliznowaceniu po zabiegu neurochirurgicznym" ("Application of isolation nets manufactured from polymer nanofibers for the prevention of excessive cicatrisation after neurosurgery" in Polish) by J. Andrychowski, M.M. Frontczak-Baniewicz, Z.M. Czernicki, D.A. Gołąbek-Sulejczak, T. Kowalczyk and T.A. Kowalewski.

\section{References}

1. Andrychowski J, Czernicki Z, Taraszewska A, Frontczak-Baniewicz M, Przytuła E, Zębala M. Granulomatous inflammation of dura mater - a rare side effect after application of hemostatic and insulation materials in case of two-stage operation of huge meningioma. Folia Neuropathol 2012; 50: 417-424.

2. Bretcanu O, Misra SK, Yunos DM, Boccaccini AR, Roy I, Kowalczyk T, Blonski S, Kowalewski TA. Electrospun nanofibrous biodegradable polyester coatings on Bioglass ${ }^{\circledR}$-based glass-ceramics for tissue engineering. Mater Chem Phys 2009; 118: 420-426.

3. Brzezicki G, Jankowski R, Blok T, Szymaś J, Huber J, Szukała A, Nowak S, Borejsza-Wysocki M. Evaluation of epidural scar formation in lumbar spine after TachoComb application - an experimental study. Neurol Neurochir Pol 2008; 42: 223-230.

4. Cauchoix J, Ficat C, Girard D. Repeat surgery after disc excision. Spine 1978; 3: 256-259.

5. Cencetti C, Bellini D, Longinotti C, Martinelli A, Matricardi P. Preparation and characterization of a new gellan gum and sulphated hyaluronic acid hydrogel designed for epidural scar prevention. J Mater Sci Mater Med 2011; 22: 263-271. 
6. Cosgrove GR, Delashaw JB, Grotenhuis JA, Tew JM, Van Loveren H, Spetzler RF, Payner T, Rosseau G, Shaffrey ME, Hopkins LN, Byrne R, Norbash A. Safety and efficiency of a novel polyethylene glycol hydrogel sealant for watertight dural repair. J Neurosurg 2007; 106: 52-58.

7. DiZerega GS, Cortese S, Rodgers KE, Block KM, Falcone SJ, Juarez TG, Berg R. A modern biomaterial for adhesion prevention. J Biomed Mater Res B Appl Biomater 2007; 81: 239-250.

8. Farrokhi MR, Vasei M, Fareghbal S, Farrokhi N. The effect of methylene blue on peridural fibrosis formation after laminectomy in rats: an experimental novel study. Spine J 2011; 11: 147-152.

9. Faulkner JR, Herrmann JE, Woo MJ, Tansey KE, Doan NB, Sofroniew MV. Reactive astrocytes protect tissue and preserve function after spinal cord injury. J Neurosci 2004; 24: 2143-2155.

10. Fransen P. Prevention of scar tissue formation in spine surgery state of the art and review of literature. J Neurosurg Sci 2011; 55: 277-281.

11. Fransen P. Reduction of postoperative pain after lumbar microdis cectomy with DuraSeal Xact Adhesion Barrier and Sealant System. Spine J 2010; 9: 751-761.

12. Fransen P. Safety of carboxymethylcellulose/polyethylene oxide for the prevention of adhesion on lumbar disc herniation - consecutive case series review. Ann Surg Innov Res 2008; 2: 2.

13. Frontczak-Baniewicz M, Chrapusta SJ, Sulejczak D. Long-term consequences of surgical brain injury - characteristics of the neu rovascular unit and formation and demise of the glial scar in a rat model. Folia Neuropathol 2011; 49: 204-218.

14. Fryczkowski R, Kowalczyk T. Nanofibres from polyaniline/polyhydroxybutyrate blends. Synth Met 2009; 159: 2266-2268.

15. Ganzer D, Giese K, Völker L, Pietzner U, Follak N, Merk H. Two-year results after lumbar microdiscectomy with and without prophylaxis of peridural fibrosis using Adcon-L Arch Orthop Trauma Surg 2003; 123: $17-21$

16. Geissler FH. Prevention of peridural fibrosis: current methodologies. Neurol Res 1999; 21: 9-22.

17. Hieb LD, Stevens DL. Spontaneous postoperative cerebrospinal fluid leaks following application of anti-adhesion barrier gel: case report and review of the literature. Spine 2001; 26: 748-751.

18. Kalogrianitis S, Barett P, Shacleford I. ADCON-L and hypotension during lumbar microdiscectomy. Br J Anaesth 2001; 87: 770-771.

19. Kato T, Haro H, Komori H, Shinomiya K. Evaluation of hyaluron ic acid sheet for the prevention of postlaminectomy adhesions. Spine J 2005; 5: 479-488.

20. Kim KD, Wang JC, Robertson DP, Brodke DS, BenDebba M, Block KM, diZerega GS. Reduction of leg pain and lower-extremity weakness for 1 year with Oxiplex/SP gel following laminectomy, laminotomy and discectomy. Neurosurg Focus 2004; 17: 1-6.

21. Kim KD, Wang JC, Robertson DP, Brodke DS, Olson EM, Du berg AC, BenDebba M, Block KM, diZerega GS. Reduction of radiculopathy and pain with Oxiplex/SP gel after laminectomy, laminotomy, and discectomy: a pilot clinical study. Spine 2003; 28: 1080-1088

22. Klopp LS, Toth JM, Welch WC, Rao S, Tai JW, Thomas KA, Turner S. Bioresorbable film for the prevention of adhesion to the anterior spine after anterolateral discectomy. Spine J 2009; 9: 411-417.

23. Kowalczyk T, Nowicka A, Elbaum D, Kowalewski TA. Electrospinning of bovine serum albumin. Optimization and the use for production of biosensors. Biomacromolecules 2008; 9: 2087-2090.
24. Kowalewski T, Lamparska D, Zembrzycki K, Kowalczyk T, inventors: Method of production of nanofibrous mats formed in an electric field. Polish Patent Application P.390140/2010-01-07 (in Polish).

25. Kurt G, Aytar MH, Doğulu F, Cemil B, Erdem O, Baykaner MK, Ceviker N. A comparison of the local effectiveness of mitomycin C, aprotinin, and Adcon-L in experimental peridural fibrosis. Surg Neurol 2008; 70: 608-613.

26. Law JD, Lehman RA, Kirsch WM. Reoperation after lumbar intervertebral disc surgery. J Neurosurg 1978; 48: 259-263.

27. Lee CK, Alexander H. Prevention of postlaminectomy scar formation. Spine 1984; 9: 305-312.

28. Lin HB, Dai JH, Wu XW, Zheng XH, Wang H, Niu SS, Wu JQ, Xu ZX. Prevention of dura adherence in spinal canal after microendoscopic discectomy by different methods: a clinical study of 165 cases. Zhonghua YiXue Za Zhi 2007; 87: 3085-3087.

29. Maliszewski M, Tymowski M, Lelek P, Bierzyńska-Macyszyn G, Majchrzak H. An attempt to use Gore-Tex surgical membrane in lumbar disc surgery. Neurol Neurochir Pol 2004; 38: 271-277.

30. North RB, Campbell JN, James CS, Conover-Walker MK, Wang H, Piantadosi S, Rybock JD, Long DM. Failed back surgery syndrome: 5-year follow up in 102 patients undergoing repeated operation. Neurosurgery 1991; 28: 685-691.

31. Nowacki M, Jundzill A, Bieniek M, Kowalczyk T, Kloskowski T, Drewa T. Modern biomaterials as hemostatic dressings in kidney nephron sparing surgery (NSS) - murine model. A preliminary report. Polimery w Medycynie 2012; 42: 35-43.

32. Preul MC, Campbell PK, Bichard WD, Spetzler RF. Application of a hydrogel sealant improves watertight closures of duraplasty onlay grafts in a canine craniotomy model. J Neurosurg 2007; 107: 642-650.

33. Reneker DH, Yarin AL, Zussman E, Xu H. Electrospinning of nanofibers from polymer solutions and melts. In: Aref $\mathrm{H}$, van der Giessen E (eds.). Adv Appl Mech 2007; 41: 43-195.

34. Richards PJ, Turner AS, Gisler SM, Kraft S, Nuss K, Mark S, Seim HB $3^{\text {rd }}$, Schense J. Reduction in postlaminectomy epidural adhesions in sheep using a fibrin sealant-based medicated adhesion barrier. J Biomed Mater Res B Appl Biomater 2010; 92: 439-446.

35. Rodgers KE, Robertson JT, Espinoza T, Oppelt W, Cortese S, diZerega GS, Berg RA. Reduction of epidural fibrosis in lumbar surgery with Oxiplex adhesion barriers of carboxymethylcellulose and polyethylene oxide. Spine 2003; 3: 277-284.

36. Rokicki G, Kowalczyk T. Cyclic carbonates and spiro-orthocarbonates - perspective monomers in the polymer chemistry of polymers. Polimery 1998; 43: 407-415.

37. Rokicki G, Kowalczyk T. Synthesis of oligocarbonate diols and their characterization by MALDI-TOF spectrometry. Polymer 2000; 41: 9013-9031.

38. Rokicki G, Kowalczyk T, Glinski M. Synthesis of six-membered cyclic carbonate monomers by disproportionation of 1,3-bis(alkoxycarbonyloxy) propanes and their polymerization. Polym J 2000; 32: 381-390.

39. Rokicki G, Piotrowska A, Kowalczyk T, Kozakiewicz J. Cyclic carbonates used in the synthesis of oligocarbonate diols involving step growth polymerization. Polimery 2001; 46: 483-493.

40. Sabuncuoğlu H, Bavbek M, Sabuncuoğlu B, Gadelha E, Köse K, Preul M. Attenuation of postlaminectomy epidural fibrosis with 
monoclonal antibodies against intercellular adhesion molecule-1 and CD-18. Spine J 2007; 7: 459-465.

41. Siqueira EB, Kranzler LI, Dharkar DD. Fibrosis of the dura mater. A cause of "failed back" syndrome. Surg Neurol 1983; 19: 168-170.

42. Slipman CW, Shin CH, Patel RK, Isaac Z, Huston CW, Lipetz JS, Lenrow DA, Braverman DL, Vresilovic EJ. Etiologies of failed back surgery syndrome. Pain Med 2002; 3: 200-214.

43. Yong-Hing K, Reilly J, de Korompay V, Kirkaldy-Willis WH. Prevention of nerve root adhesions after laminectomy. Spine 1980; 5: 59-64. 